\title{
A Discussion of the Deadlock Confronted by Chinese Writers of English Academic Articles
}

\author{
Jie Sun*, Yan Wang \\ Shan Xi Datong University, Datong, Shanxi, China \\ Email: 179419478@qq.com
}

\begin{abstract}
As a consequence of receiving frequent complaints from students and colleagues about their difficulties in writing papers in English, I have to reconsider the deadlock confronted by Chinese writers of English academic articles. Obviously, these writers have similar difficulties in approaching academic writing, not because lack of professional knowledge, but because the ability of processing language is not handy enough, though the majority of them demonstrate good lexical and grammatical knowledge, or even discourse knowledge of the target language. Therefore, summary and exploitation of the deadlock confronted by them facilitates the improvements of language efficiency in expressing ideas. If they can build certain cultural awareness before constructing ideas, writing in English may not be so problematic as they anticipate. In this article, the deadlock confronted by Chinese writers based on a theoretical research about EAL or EFL academic writing and interview with carefully selected writers is concluded as three major difficulties: text borrowing, critical writing, as well as structural and ideological diversity between L1 and L2. They should be highlighted as the most conspicuous problems for Chinese writers. However, most of the difficulties originate from cultural difference and language obstacles posed by it, which needs to be realized by Chinese EFL writers. To solve the problems, I recommend teachers and learners to adopt comparative approach and text-based approach which emphasize cultural awareness in training writing skills.
\end{abstract}

Keywords: Deadlock; Chinese writers; English academic articles

\section{Introduction}

Writing for an academic community like a college or university is not as easy as many people expect. It poses considerable difficulties for writers using English as an additional language (EAL), or a foreign language (EFL) than for native speakers to write the disciplinary discourses on numerous subjects. For advanced EFL students at graduate and post-graduate level, writing can be even more complicated since a relatively high standard and often specialized language is required. The purpose of this essay is to describe the deadlock faced by writers from China based on the generalization of relevant literature in this field, as well as interview with some of my students and colleagues, by whom the deadlock is reported. Then, a critical evaluation will be given in order to sort out the crucial attributions to the hardness of achieving a satisfactory goal in English academic writing. The largest influential factor is, as I perceive, cultural and language obstacle. The discussion over the deadlock and its attributions may indicate feasible solutions to the problem.

\section{Description of the Deadlock}

Writing is an essential skill for students and scholars to survive in academic contexts. For example, to compile a research report or a dissertation needs not only one's knowledge in his or her subject area, but also the correspondent writing skills of that language in use. Also, written assignments are the most frequently employed measurement for one's academic performance. Through study of samples of graduate thesis written by Chinese students, it is not difficult to generalize the common problems facing these students, especially at a higher level where using English to communicate ideas is no longer a bitter lemon to bite on everyday occasions. They still have deadlock of writing, however, which can be found in the areas of text borrowing, critical writing, structural and ideological diversity between L1 and L2. Similar problems also exist in undergraduate and graduate papers of English majors. 
First of all, many students have the problem of textual borrowing, or incorporating other people's work naturally and intelligently into their own writing. 'Many of the genres commonly found in graduate-level writing require sophisticated weaving of prior texts into a larger piece of written discourse' (Barks and Watts 2001: 247), and this can be extremely difficult for EAL or EFL students. Barks and Watts (2001) has summarized three contributing factors to the 'issues surrounding textual borrowing' as 'the problematic and dynamic concepts of authorship and originality', 'different culture and educational practices', and 'the complex nature of language learning itself'. They argue that there is lack of consistency of the concepts of authorship and originality within and without western culture. They also point out that people from different cultural background may have different perspective towards the conventions of textual borrowing. For example, some cultural and educational practices like that in China tend to be more tolerant of 'plagiarism' because Chinese value memorization as a standard and effective learning style. Barks and Watts (2001: 249) state that 'achieving the level of language proficiency necessary not just to survive but to thrive in the English-speaking academic context is clearly a complex task for a nonnative speaker.' They point out that as one aspect of language proficiency, the ability to integrate others' work into their own work requires sophisticated knowledge and skills, such as reading comprehension ability, the skills of processing and synthesizing reading materials, linguistic knowledge and the necessary background knowledge of one's subject matter. Non-native writers are doubly challenged by the emerging difficulties around text borrowing because they are unfamiliar with the writing culture of English and have limited linguistic proficiency. The situation gets worse if they apply the mistakenly interpreted reading materials into their written work.

Second, quite a lot of students find it difficult to write critically, though they are expected to write like 'experts in training' rather than 'receivers and demonstrators of knowledge' (Belcher 1995: 137). In other words, most Anglophone educators encourage college students from various disciplinary areas to read and write critically on their way of becoming specialized scholars. However, some students and especially EFL students are reluctant to challenge established authority. One reason for this reluctance simply lies in the lack of confidence. Once they have accumulated enough specialized knowledge and become familiar with the critical and analytical way of learning, they begin to write critically. While another reason is culturally dominated, to which difficulties relate usually take extra time and effort to overcome. For example, teachers in the university of Auckland have noticed the relative unwillingness of Chinese writers to criticize other people's work. They design a lot of group work tasks in teaching academic writing, preparing students from China and other Asian countries with necessary skills of thinking, discussion and writing critically. Every student who joins the group must accomplish equal amount of work in order to get a pass score. This is because Chinese students are perhaps too cautious to critique other people's work for the sake of so-called 'social harmony'. Their cultural background does not encourage them to do so, which creates for them either the difficulty of referring to the source and its authors, or the difficulty of writing critically by themselves.

Finally, some EFL students, even if at or above graduate level, have the difficulties of organizing rhetorical structure and communicating ideas with their readers, owing to the strong influence of their first languages. Hamp-Lyons and Zhang (2001) in their research report compare different attitudes towards rhetorical diversity between Chinese-speaking and native English teachers who participated in an experiment on assessing two problematic compositions of Chinese students. They conclude that this diversity has two levels: the level of structure and that of ideology. The former has to do with the way of structural organization within and between paragraphs, whilst the latter focuses on the way of forming ideas and perspectives. The authors' purpose of introducing the diversity is to provide useful hints for assessing students' written work. Meanwhile, it suggests how strong the influence of the first language over English might be in terms of structure and ideology, so that it can pose considerable difficulty for EFL students when they strive to write successfully for academic purposes. Jin and Cortazzi (1993: 91-92) also illustrates the structural and ideological difference between Chinese and English writing systems in their paper Cultural Orientation and Academic Language Use, which affects the production of writing of even post-graduate EFL students. On one hand, as they state, the contrasted views of the two languages on the discourse patterns may be contributors. On the other hand, the different ways of thinking lead to occurrence of additional difficulties, from constructing ideas to seeking help from tutors. For example, Chinese students, out of the collective way of thinking, may get used to do the research according to the need of the authority instead of personal interests, thus they are passive about choosing a research topic. Generally speaking, the difficulties for advanced EFL students with rhetorical structure and ideology often 
originate from a potent influence of one's native language and culture.

There are implicit problems that hamper students from writing successfully in academic English. Schneider and Fujishima (1995) point out in their account of one foreign student's struggle to make his academic achievements that the difficulties challenging this student's writing can be divided into several categories: 'English language proficiency', 'sensitivity to sociolinguistic norms', 'motivation for learning', 'learner strategies' and 'other personal factors'. Nevertheless, if the problems of language use and typical personal factors are excluded, writing academic papers is still difficult. At a higher English proficiency level, the deadlock of Chinese writers lies in text borrowing, critical writing, as well as structural and ideological diversity between L1 and L2.

In order to check the authenticity of the concluded difficulties, I interviewed two groups of Chinese writers: group one are senior students of English major who were busy preparing thesis for their graduation; group two are my colleagues - teachers from different departments who have experience in writing papers in English. Each group involved 10 people. All the interviewees are from a local university in China. They have proved English language proficiency for high intermediate or advanced level, and are competent writers of L1, for I need to sort out the dominant difficulties other than language use from a rather academic point of view. The result of the interview is summarized in the list below.

- All interviewees agreed that text borrowing, critical thinking, and structural and ideological diversity between L1 and L2 were 3 most difficult areas to adapt to.

- 10 out of 20 reported that text borrowing was the most difficult part of writing, even if they had already been familiar with APA referencing style.

- The difficulty of text borrowing mainly arose from processing reading materials. On one hand, they needed more reading time; on the other hand, sometimes it was hard to decide whether citation of the source text is necessary or not.

- 6 of 20 reflected that critical thinking was the leading difficulty because they were seldom trained to challenge the established authority.

- 4 of 20 thought writing in English was difficult owing to L1 influence. They could not get used to constructing ideas in English, and would rather think in Chinese firstly and translate their view later.

- All interviewees agreed that if they were given more time and appropriate tutoring the difficulties could be overcome.

\section{Crucial Attributions}

Writing for academic purposes involves various knowledge and skills. It is not linear but a process that contains several dimensions. For instance, when passing through the stages of planning and revision to compose an essay, we need to do a set of jobs ranging from surveying source materials to editing drafts. At the same time, we must follow the academic conventions and make the structure of our articles clear and ideas communicative to our audience. During the composing process, we apply all kinds of strategies, whether consciously or unconsciously. Comparing with native speakers, the difficulties of writing always double for Chinese students, due to their limited language competence and unfamiliarity with different discourse patterns. Moreover, some ethnic students find it difficult to adapt the western way of thinking and reasoning to their own view.

At the stance of an EAL or EFL student, no matter what their specialties are, I feel that cultural diversity is indeed a great challenge to producing academic discourses in English. Many difficulties raised in the writing practice have a cultural origin. Here, 'culture' means 'the total pattern of beliefs, customs, institutions, objects, and techniques that characterize the life of a human community' (Deng and Liu 1989: 3). It certainly affects writing, which is a tool of expressing human thoughts and beliefs. Bark and Watts' exploration of the differences in source text use across cultures, and Belcher's comments on the barriers of critical writing for Chinese students remind me the different attitudes of Chinese towards plagiarism and the existing reluctance to challenge scholarly work. Belcher mentioned the term 'experts in training' to indicate that graduate or post-graduate students are expected to write critically like real experts or scholars, but this contradicts what I was taught in china since my childhood. To some extent, Chinese educators do encourage their students to think and write critically, but they constantly give students such instructions as 'Be modest', 'Do not pretend to be experts'. Actually, some Chinese authors avoid giving the impression that they are experts on their subject matter. For example, Deng and Liu (1989: 110) have 
noticed that the conventional use of titles in scholarly papers and articles written in Chinese is somewhat strange to English speakers. It is common for a Chinese writer to add some words showing humility about their work in titles. Whereas English authors may think it ridiculous to write a title like 'A Superficial Discussion of ...', or 'My Humble Opinions on...' Furthermore, as Hamp-Lyons and Zhang (2001) indicate in World Englishes: Issues in and from academic writing assessment, the influence of students' L1 and home culture is an explanation to the emergence of some problems, in terms of both rhetorical pattern and ideology.

There are other difficulties evident in some sample academic texts that I have studied or students' papers that are marked by their teachers as 'unclear expression of ideas', one of which is the lack of language proficiency. In a broad sense, to achieve this proficiency, students need to have a good knowledge of vocabulary, grammar and to be familiar with the discourse structure of academic English. In addition, they must be aware of the cultural differences and clearly understand academic conventions. However, this is still insufficient. Reading comprehension ability and the ability to integrate reading into reading are also important. On the difficulties of comprehending texts, Bark and Watts (2001: 250) state that inexperienced writers at graduate level may 'approach reading-to-write tasks with limited or misguided strategies and inadequate task interpretation'. They did not notice in their article that a relatively low speed of reading increases the difficulty of applying reading materials. Comparing with native speakers, foreign students need more time to read through and synthesize materials into their writing. Being impatient to read for a long time before drafting can push students into patchwriting, which is normally considered as a kind of plagiarism. Interestingly, many Chinese scholars challenge the western viewpoint towards it. Instead, they would rather regard it as a natural stage on the way of becoming mature writers and accepts it as an effective teaching strategy to students moving at this stage.

Obviously, cultural and language obstacles are two major attributions to various difficulties faced by Chinese English writers even at higher academic level. It does not mean they are the most conspicuous obstacles to every student. The major difficulties for some students are caused by motivation, learner strategies and other personal factors. But as they approach English academic writing, the deadlock arising from cultural difference may be more thorny and hard to overcome if they are unconscious of the internal cause. Therefore, to build culture awareness is an important solution. Chinese EFL writers and scholars should adopt the comparative approach more often. Before writing academic articles in English, they should understand writing conventions, together with the logic reasoning steps of the target language. Comparison between Chinese and English articles under the same topic is always necessary, since it helps the writer voluntarily switch to the thinking mode of another culture. They may constantly ask themselves some questions like 'Do I need to cite experts' words in this paragraph?', 'Is it important to suggest a different opinion at this step?', 'What will a native speaker do in order to summarize this?', etc.

\section{Conclusion}

The difficulties of academic writing among Chinese EAL or EFL writers often arise from text borrowing, critical writing and following rhetorical conventions. Although it is not the case to all the students, cultural and language barriers are the major contributors that make their writing problematic. As increasing numbers of students pursuing graduate and post-graduate study need to write their papers in English, these problems have gained growing concern among students, teachers and the academic institutions they enrolled in. One possible solution to the problems relating to culture is to let both students and educators be aware of the difference and then seek 'culture synergy', in which 'adaptation, rather than assimilation' is emphasized (Jin \& Cortazzi 1993: 95). To teachers, it is necessary to construct a cultural syllabus, that is, EAL or ESL students should be given opportunities to explicitly learn the rules of Western writing conventions, patterns of cognition, and attitudes to text before brainstorming and constructing ideas. To learners, just as Byram and Fleming (1998) suggest, language learning should follow the cognitive process that insight and increased understanding of the society and culture of both L1 and L2 is promoted.

With regard to language problems, experienced teachers may propose the text-based approach as a fast solution to some students' problems. For example, when teaching educated adults who are already competent writers in their first language, a teacher of business or scientific English might focus on the features of commercial or technical texts, asking the students to do necessary discourse analysis before compiling their own piece. That is why I recommend my students to study some standard academic articles 
in the relevant research field before they come to compile their own piece. Analysis of academic discourse paragraph by paragraph increases writers' confidence in completing a paper that caters for the appetite of native English audience. They may clearly realize that copy of any word of the sample text is forbidden, but imitation of the structure and the writing style - the way of constructing ideas is definitely applicable, especially when the due date is near.

It is worthwhile to combine comparative approach and text-based approach in training writing because both of them emphasize cultural awareness. After all, the choice of teaching method should meet the specific needs of learners from different cultural background. To writers from China, being aware of their common deadlock and its influential factors may assist them in adapting English academic writing within short period.

\section{References}

1. Barks, D. and Watts, P. (2001) 'Textual Borrowing Strategies for Graduate-Level ESL Writers' in Belcher, D. and Hirvela, A. (eds) Linking Literarcies: Perspective on L2 Reading-Writing Connections, Michigan: University of Michigan Press

2. Belcher, D. (1995) 'Writing Critically Across the Curriculum' in Belcher, D. and Braine, G. (eds) Academic Writing in a Second Language, New Jersey: Ablex

3. Byram, M. and Fleming, M. (eds) (1998) Language Learning in Intercultural Perspective: Approaches Through Drama and Ethnography, Cambridge: Cambridge University Press

4. Deng, Yanchang. and Liu Runqing. (1989) Language and Culture, Beijing: Foreign language teaching and research Press

5. Hamp-Lyons, L. and Wenxia Zhang, Bonnie. (2001) 'World Englishes: Issues in and from academic writing assessment' in Flowerdew, J. and Peacock, M. (eds) Research Perspectives on English for Academic Purposes, Cambridge: Cambridge University Press

6. Jin, L. and Cortazzi, C. (1993) 'Cultural Orientation and Academic Language Use' in Graddol, D., Thompson, L. and Byram, M (eds) Language and Culture, Clevedon: Multilingual Matters

7. Schneider, M.L. and Fujishima, N.K. (1995) 'When Practice Doesn't Make Perfect: The Case of a Graduate ESL Student' in Belcher, D. and Braine, G. (eds) Academic Writing in a Second Language, New Jersey: Ablex 